\title{
Tres momentos en la conformación de la identidad nacional hondureña
}

\section{Mario R. Argueta}

Honduras inicia el siglo XX careciendo aún de una unidad territorial y de un sentimiento nacional. Es cierto que con la implantación de una Reforma Liberal iniciada a partir de 1876, bajo la influencia directa del movimiento político iniciado en Guatemala en 1871, con la ayuda de la Administración Juárez de México, se intentó echar las bases de una visión historiográfica que interpretara el pasado y el presente en función de los intereses estatales, influidos por las concepciones filosóficas positivistas.

Los resultados no correspondieron a las expectativas. Pese a la exaltación de elementos patrióticos y del culto a los héroes locales, la idea de Honduras y lo hondureño aun se encontraba poco desarrollada entre la mayoría de la población, que era abrumadoramente rural y campesina. Existían diversas razones para ello: lo escaso y disperso de la población, el aislamiento del país, aun con respecto a sus vecinos en razón de ser el país más montañoso de América Central, la situación subordinada de las elites nacionales con respecto al capital extranjero, consolidado ya en la industria minera y ampliando sus inversiones en el rubro bananero, al amparo de las generosas concesiones en tierras y en exención de impuestos de importación de los gobernantes hondureños a cambio de ferrocarriles a ser construidos por las empresas fruteras que vincularían los puertos del Caribe con los centros poblados del interior.

De allí que la Honduras de albores vigésimoseculares era una nación todavía no vertebrada; más correctamente, un conjunto 
de regiones semiaisladas, autosuficientes en sus necesidades básicas, con una economía ganadera y minero-mercantil concentrada en la zona centro-sur, en manos de las clases altas locales, que encontraban en el usufructo de estas actividades y en sus disputas por el control del Estado, las únicas alternativas disponibles para su subsistencia y acumulación de capital. El comercio mayorista y al detalle, salvo aisladas excepciones, lo detentaban inmigrantes alemanes, merced a su monopolio en el sistema de transporte por medio de lanchones entre tierra firme (puerto de San Lorenzo) y la Isla del Tigre (puerto de Amapala), en el Golfo de Fonseca, su red de tiendas establecidas en los centros urbanos y las facilidades de crédito otorgadas a sus clientes. Desde la década de 1890 inmigrantes palestinos habían empezado a llegar, en pequeños números y de manera espontánea, a la Costa Caribeña del país, donde el negocio bananero en creciente expansión ofrecía oportunidades comerciales a medida que la zona se iba poblando $y$ urbanizando. Ellos constituyeron el embrión de una posterior clase empresarial que, además de la actividad mercantil, incursionó con éxito en la industria.

La historia política hondureña hasta 1933 se caracterizó, por una parte, por las guerras civiles entre dos facciones procedentes de un mismo tronco liberal, autodesignadas con los nombres Partido Liberal y Partido Nacional, disputándose el control del aparato estatal. En ellas participaban diversos sectores sociales: si los caudillos salvo excepciones, procedían de las filas terratenientes, profesionales y militares, los soldados venían de los sectores campesinos, trabajadores agrícolas y urbanos. Por otra, a la par de la tradicional intervención de los países vecinos: particularmente Guatemala y El Salvador $y$, en fecha posterior, Nicaragua, cuya aprobación respecto al mandatario hondureño de turno, era indispensable para su permanencia en el poder, se va perfilando la presencia diplomática de los Estados Unidos, generalmente actuando como promotor $y$ defensor de los capitalistas de esa nacionalidad. Las distintas modalidades de la política exterior norteamericana en estas primeras décadas del siglo: política del gran garrote, diplomacia de las cañoneras, diplomacia del dólar, fueron aplicadas en forma directa, aliados el palo y la zanahoria, en los países de la cuenca Caribeña. Así, la intervención de las 
aduanas y el otorgamiento de préstamos con el fin de ir desplazando la influencia europea en la región, aplicado inicialmente en la República Dominicana, fue después intentado en Honduras, en 1911, con la firma del Tratado Knox-Paredes, rechazado por el Congreso hondureño.

Los desembarcos de "marines" fueron frecuentes por periodos cortos, en ciudades-puertos de litoral caribeño: Puerto Cortés, Tela, La Ceiba, cuando se intensificaban los conflictos armados locales. Generalmente, era el Cónsul estadunidense quien determinaba la gravedad de la situación y, de acuerdo a su criterio, llamaba o no, al escuadrón naval norteamericano más cercano a la zona.

La presión diplomática norteamericana, a través de su Ministro Plenipotenciario en Honduras, contribuyó poderosamente a la renuncia a la Presidencia del Mandatario Francisco Bertrand en 1919 , además de sus intentos por imponer en la sucesión presidencial a su cuñado, lo que originó la alianza de la oposición en su contra.

En enero de 1924, al haberse roto el orden constitucional y continuar de facto, en el poder, el general Rafael López Gutiérrez, la guerra civil estalló nuevamente en Honduras. El fallecimiento de éste no significó el fin del conflicto; por el contrario, pareció recrudecerse. El ministro estadunidense acreditado ante nuestro país, Franklin Morales solicitó la llegada de doscientos infantes de marina, a la capital de Honduras. Nunca antes habían desembarcado en Tegucigalpa. El Consejo de Ministros, que ejercía nominalmente el mando, en nota firmada por el Canciller Rómulo E. Durón, protestó tal acto el 19 de marzo de ese año.

En uno de sus párrafos se afirmaba:

El Consejo de Ministros no puede menos que manifestar a Vuestra Excelencia su sorpresa por el hecho del desembarco y la venida de ese cuerpo de soldados a esta capital, sin solicitud ni autorización del Gobierno de la República, y en consecuencia, lo considera como un agravio a la soberanía e independencia del país. 
También una parte de la intelectualidad capitalina, dirigida por Froylán Turcios, editó el diario Boletín de la Defensa Nacional. En su número primero, escribía Turcios:

Estados Unidos no tiene ningún derecho para mezclarse en nuestros asuntos internos.

Ningún centroamericano en que vibre la más insignificante emoción de patriotismo podrá reconocer jamás el menor derecho al Gobierno de los Estados Unidos para inmiscuirse en nuestros asuntos internos. $\mathrm{Si}$, desventuradamente vivimos con el dicterio en los labios o con el rifle al hombro, destrozándonos como fieros enemigos, con saña de los gallos de pelea, esto sólo nos incumbre a nosotros y nada le importa de ello a ninguna nación extranjera. Que no se nos diga cínicamente, que acuden en nuestro auxilio por piadosa humanidad, pues lo cierto es que tal ayuda es interesada, nacida de un instinto pirata. $Y$ aun cuando no fuera así, sería ignominiosa para nuestro civismo y atentatoria para nuestra soberanía. Somos nosotros, y solamente nosotros, los que debemos buscar el remedio a nuestros males de ambiente y de raza y no los extraños y los entrometidos.

Algunos de los colaboradores del Boletín, fueron: Alfonso Guillén Zelaya y Porfirio Hernández, que posteriormente se trasladaron a México, Visitación Padilla, Adán Canales, Rafael Díaz Chávez (Jefe del Partido Unionista Centroamericano), entre otros. La referida publicación declaraba que su aparición tenía dos objetivos:

apresurar, con sus tenaces trabajos, la salida del enemigo común y hacer conciencia nacional.

Esas manifestaciones nacionalistas y anti-imperialistas de una parte de la intelectualidad nacional, encontraban antecedentes en hombres de letras como Paulino Valladares, para quien la 
intervención norteamericana en Centroamérica, ya de manera sistemática y definitiva, databa de 1906, cuando el presidente Roosevelt de Estados Unidos, y el mandatario Porfirio Díaz de México, convocaron a las naciones centroamericanas a bordo del buque de guerra Marblehead, al intervenir como mediadores en la guerra entre Guatemala y El Salvador. Afirmaba Valladares:

La política internacional de Centroamérica tiene su centro de gravedad en Washington, de una manera definitiva desde 1906... Y no sólo dependemos de la voluntad soberana del Departamento de Estado, sino que allá intrigamos, gobiernos contra gobiernos para hacernos daño mutuo... la intervención de Estados Unidos en Centroamérica es de larga data. $Y$ depende de un modo sistemático y definitivo desde los preliminares firmados a bordo del Marblehead en 1906.

Estos juicios fueron escritos en 1914 y 1922 respectivamente. Entre 1910 y 1913, otro hondureño, Salvador Turcios Ramírez escribió artículos que, bajo el título colectivo Al margen del Imperialismo Yanki, aparecieron, en formato de libro, en 1915. Así se pronunciaba:

Nosotros yacemos dentro de la zona influenciada y explotada por los Estados Unidos. Somos sus tributarios económicos, luego entonces, hemos sido conquistados prácticamente por aquella Nación... El dilema está planteado para la existencia independiente de Centroamérica. $O$ nos unimos en un abrazo de orden y de trabajo, o desaparecemos ante la voracidad de las insaciables avideces de los cartagineses del Norte. La actual situación política de nuestras minúsculas nacionalidades, es clara y peligrosa al mismo tiempo. Puede resumirse así: de un lado la cobarde criminalidad de los aborígenes que solicitan de rodillas el protectorado, y del otro, la franca complicidad de los imperialistas que ocupan el Capitolio de Washington, y 
que obedecen ciegamente al poder incontrarrestable de la plutocracia que vive parapetada tras las enormes montañas de oro de Wall Street... Que la política expansionista de los Estados Unidos, es un hecho evidente, que no necesita demostración, lo están probando hasta el exceso los directores de la cosa pública que, en aquella nación, como en las de Europa y Asia, que se han engrandecido por sus prácticas imperialistas, son abiertamente agresivas a la dignidad humana y al concierto de familia de las naciones libres.

Veamos un segundo momento en ese proceso inconcluso de conformación de la identidad nacional. Este se dio en 1954 en las plantaciones bananeras de la United Fruit Company en el litoral caribeño de Honduras, cuando las tensiones resultantes de la Guerra Fría se encontraban en su momento más álgido. Estados Unidos se preparaban para el derrocamiento del régimen de Jacobo Arbenz en Guatemala. Un año antes había exitosamente derrocado el gobierno nacionalista del primer Ministro Iraní Mohamed Mossadeq.

No entraremos en detalles respecto a la evolución de este movimiento social reivindicativo, el más significativo en la historia laboral hondureña. Lo que nos interesa resaltar, para propósitos de este trabajo es el apoyo que los trabajadores agrícolas en huelga encontraron por parte no sólo de otros núcleos proletarios que, en actos de solidaridad, igualmente se declararon en paro en sus centros laborales, tanto en la Costa Norte como en el interior del país, sino también de otros sectores de la estructura social: burguesía, estudiantes, intelectuales. $\mathrm{Y}$ es que el componente nacionalista estaba allí presente. Se trataba de reivindicaciones salariales y organizativas que enfrentaban a miles de obreros (unos 25,000 ) nacionales contra la más poderosa empresa frutera norteamericana en Centroamérica y el Caribe, de capital norteamericano. De tal suerte que el apoyo y simpatía que los movimientos huelguísticos encontraron entre distintas capas sociales de la población se debía no sólo a que se consideraban justas y razonables las peticiones elevadas a la empresa por parte de los trabajadores sino al hecho que ésta era vista como un monopolio 
extranjero que había llegado a obtener, vía concesiones gubernamentales, las tierras más fértiles del país, una cadena de comisariatos o tiendas de ventas al detalle en el seno del enclave bananero que competían ventajosamente con el comercio local, el banco más poderoso en el país, amén de empresas de bebidas gaseosas y cerveza, entre otras inversiones que abarcaban plantas de energía eléctrica, hielo, calzado y una empresa de comunicaciones internacionales.

Además de incrementos salariales, los huelguistas demandaban mejores condiciones de trabajo, tratamiento médico adecuado en los hospitales de la empresa, cese a la discriminación racial, pago semanal, abolición de los despidos arbitrarios, salario igual por trabajo igual, un sistema de jubilación para los estibadores, enseñanza primaria "completamente laica y gratuita" para todos los hijos de los empleados y trabajadores, garantías de que no habría represalias contra los huelguistas, pago completo de sus salarios a todos los huelguistas. Al cabo de 69 días de paro, se llegó a un acuerdo con la empresa frutera que no colmó las expectativas planteadas inicialmente por los huelguistas. No obstante, tal como afirma Víctor Meza:

\begin{abstract}
A partir de mayo de 1954 no era posible ya desentenderse de la clase obrera y continuar ignorando sus demandas. En este sentido, la huelga bananera de 1954 significó un punto de ruptura crucial en el proceso de dominación neocolonial en el país. La burguesía y los terratenientes hondureños al igual que los emisarios del capital imperialista se vieron obligados a reconocer legalmente el derecho de los trabajadores a la libre sindicalización, dando inicio así a una reforma jurídica de trascendental importancia que legalizó los sindicatos, reconoció los derechos más elementales de la clase obrera y concluyó con la emisión en el año de 1959 del Código de Trabajo. ${ }^{1}$
\end{abstract}

\footnotetext{
Meza, Víctor. Historia del movimiento obrero hondureño. Tegucigalpa, Guaymuras, 1981, pp.97-98.
} 
Puede deducirse de esta cita que las implicaciones de este movimiento social tuvieron repercusiones, en el corto plazo, a nivel nacional. Los trabajadores bananeros alcanzaron conquistas que beneficiaron a toda la clase obrera hondureña, que, teniendo como referencia las jornadas de 1954, llegó a constituirse durante varias décadas como uno de los mejor organizados y de mayor peso, como grupo de presión e interés, en el ámbito centroamericano.

El enfrentamiento bélico con El Salvador, en 1969, tiene diversas causales: demográficas, ecológicas, fronterizas, económicas. No serán examinadas. Nos interesa detallar algunas de las secuelas que contribuyeron a la formación de un sentimiento de identidad nacional. En el aspecto militar, Honduras llevó la peor parte y eso no fue casual. Su ejército, con excepción de la rama aérea, no contaba con el armamento adecuado ni con el entrenamiento necesario como para repeler el ataque emprendido por otro país. Carecía de una tradición institucional de larga trayectoria, por el hecho de ser muy reciente su creación, como ente corporativo. Y fue bajo el estímulo de los Estados Unidos que se dieron los primeros pasos en su modernización, a partir de 1950.

Lo que evitó el colapso en los frentes de batalla fue el apoyo irrestricto de la población civil a la defensa del territorio y a la contención de la penetración invasora. Los sectores urbanos aportaron recursos económicos, mediante la compra de bonos, para la adquisición de armamento y los habitantes rurales abastecieron de alimentos a los combatientes.

La salvaguarda de la soberanía había corrido así, en mayor o menor medida, a cargo de la población toda. Las gestiones diplomáticas de la Organización de Estados Americanos fueron también oportunas para evitar un mayor derramamiento de sangre y el control permanente de territorio nacional por parte del país vecino.

Al igual que ocurrió con Bolivia, luego de su fracaso en la Guerra del Chaco (1932-1935), surgióoun sentimiento de cooperación y de cambio entre los sectores castreȟse y civil. Ambos empezaron a cuestionar las razones estructưrales que habían hecho posible la pérdida, llegando inclúso a cuestionarse el 
modelo de desarrollo que hasta entonces habían impulsado las elites locales.

Igualmente, Honduras reconsideró sus relaciones comerciales con las otras repúblicas centroamericanas signatarias del Mercado Común Centroamericano, conduciendo a su retiro del esquema integracionista a lo largo de la década de los años setenta, lo que facilitó al sector industrial y comercial hondureño abastecer el mercado interno sin contar con la competencia de sus homólogos del Istmo.

De este modo, la guerra colocó en la agenda nacional los problemas del desarrollo económico e integración nacional. La discusión generada en torno a ellos involucró, por vez primera en la historia hondureña, no sólo a los grupos tradicionales de presión, sino, igualmente, a los sectores obreros y campesinos organizados, sentados en la misma mesa con la dirigencia política, empresarial y militar. Este fue el embrión del intento aplicado durante 19711972 por implantar un Gobierno de Unidad Nacional, Al fracasar este intento bi-partidista, que, en su momento fue criticado como una alianza de las élites tradicionales de poder, se dio una crisis de credibilidad con respecto a los partidos políticos tradicionales. EI Ejército, aplicando un reformismo, al estilo peruano, que, con altibajos, impulsó reformas sobre todo en materia agraria, que evitaron que la polarización entre las distintas clases sociales desembocara en la guerra civil, como aconteció en Guatemala y El Salvador.

Hemos pasado revista a tres instancias en el desarrollo histórico de Honduras que, en grado diverso, contribuyeron hacia la conformación de la identidad nacional de la nación hondureña. 